\title{
A NEW APPROACH TO WOOD PROTECTION: PRELIMINARY STUDY OF BIOLOGICALLY SYNTHESIZED COPPER OXIDE NANOPARTICLE FORMULATION AS AN ENVIRONMENTAL FRIENDLY WOOD PROTECTANT AGAINST DECAY FUNGI AND TERMITES
}

\author{
K. S. Shiny ${ }^{1, \star}$, R. Sundararaj ${ }^{1}$, N. Mamatha ${ }^{1}$, B. Lingappa ${ }^{1}$
}

\begin{abstract}
Nanoparticles have addressed many challenges in science and technology and wood science research is one such field that has benefitted from application of metal nanoparticles. The metal nanoparticles that are commercially available for wood protection are synthesised by physical and chemical methods which produces toxic by-products and are expensive. The current study deals with a new approach for utilization of metal nanoparticle for wood protection in an ecofriendly and cost effective way. Metal nanoparticles were synthesised using plant extracts that are known to have wood preservative properties. The synergistic effects of the intrinsic property of plant extracts along with the biocidal property of metal nanoparticles were utilized. Copper oxide nanoparticles were synthesised using leaf extracts of Neem (Azadirachta indica), Pongamia (Pongamia pinnata), Lantana (Lantana camara) and extract of orange peel (Citrus reticulata). The effectiveness of the synthesised plant extract and copper oxide nanoparticle formulation is tested against wood decay fungi using agar mixed with the test substance. Graveyard test is employed to assess the effect of the copper oxide nanoparticle formulation against termites. Preliminary results are promising and studies are progressing to develop a stable and environmentally benign wood preservative formulation of metal nanoparticles and plant extracts.
\end{abstract}

Keywords: Antitermite activity, biological synthesis, brown-rot fungi, plant extracts, white-rot fungi, wood protection.

\section{INTRODUCTION}

In last decade, nanoparticles have been reported to resolve many impeding technological challenges in various fields of science like engineering, medicine, water purification, catalysis etc. to name among a few (Klefenz 2004, Goodsell 2004, Chan and Nie 1998, Colvin et al. 1994, Tan et al. 2006, Lee et al. 2008, Pissuwan et al. 2006, Cai et al. 2008, Cao 2004). One such area in which nanoparticles, mainly metal nanoparticles have proved to be instrumental is wood protection. The metal nanoparticles used in wood protection are generally copper, zinc and boron. Lot of literature is available on the use of nanometals for wood protection (Clausen 2007, Clausen et al. 2010, Kartal et al. 2009, Akhtari and Arefkhani 2010, Nair et al. 2017). Terzi et al. (2016) reported the role of nanoparticles of $\mathrm{ZnO}, \mathrm{B}_{2} \mathrm{O}_{3}, \mathrm{CuO}, \mathrm{TiO}_{2}, \mathrm{CeO}_{2}$ and $\mathrm{SnO}_{2}$ in prevention of fungal decay, mold growth and termite attack on wood along with their effect on weathering properties and water repellency. Mishra et al. (2018) reported the impact of nanoparticles on the wood coating and preservation treatments based on survey of the registered patents. The report gave an overview of the scientifically most followed trends on nanoparticle utilization in wood science and wood protection depicted by recently filed patents. Even though nanoparticles have addressed various issues of wood science in a more efficient way than the traditional methods of employing metal salts, commercially available nanoparticles are synthesized by physical and chemical methods. The disadvantage of physical synthesis method is that they are energy intensive and are expensive. Chemical synthesis methods involve the use of many toxic chemicals which limits the applications of chemically synthesized nanoparticles, especially in medical field and are not environmental friendly (Vijayaraghavan and Ashokkumar 2017). Search for a biocompatible, non-toxic 
and ecofriendly method of nanoparticle synthesis lead to the development of biological synthesis route for production of nanoparticles. Biological synthesis of nanoparticles involves the use of biomaterials such as bacteria (Hulkoti and Taranathm 2014), fungi (Dhillon et al. 2012), yeast (Moghaddam et al. 2015), virus (Dujardin et al. 2003), microalgae (Schrofel et al. 2011), macroalgae (Singaravelu et al. 2007) and plant extracts (Mittal et al. 2013). Of all these biomaterials, plant extracts are considered more advantageous for the synthesis due to their availability, renewable nature, simplicity of process, efficiency, rate and stability of synthesized nanoparticles and cost effectiveness (Vijayaraghavan and Ashokkumar 2017, Iravani 2011).

Wood science researchers so far have not explored the possibility of utilizing biologically synthesized nanomaterials for wood protection. Plant extracts contain numerous organic molecules like carbohydrates, proteins, vitamins, alkaloids, enzymes etc. These molecules can act as either potential reducing or stabilizing agents for the synthesis of nanoparticles. In addition to the ecofriendliness and cost effectiveness, plant extract based synthesis combines the intrinsic properties of plants with the biocidal properties of nanoparticles via the synergistic effect. The plant extracts which have both wood preservative properties and are capable of synthesizing metal nanoparticles are to be selected. The synergistic effect of the plant extract with the biocidal nature of metal nanoparticles also contributes to the efficacy of a wood protectant. There are several factors that affect synthesis of nanoparticles using plant extracts, its characterization and application namely origin of plant material, method of extraction employed and the solvents used. The temperature employed, $\mathrm{pH}$-value and the reaction time also plays an important role in the size and shape of nanoparticles produced (Vijayaraghavan and Ashokkumar 2017).

This research reports the synthesis of copper oxide nanoparticles using plant extracts and testing its efficacy as a wood preservative. Leaf extracts of Neem (Azadirachta indica), Pongamia (Pongamia pinnata), Lantana (Lantana camara) and extract of orange peel (Citrus reticulata) were used to synthesize copper nanoparticles. All these plants have reported wood preservative properties (Macias et al. 2005, Sotannde et al. 2011, Machado et al. 2013, Venmalar 2017, Gupta et al. 2017) and are reported in the synthesis of metal nanoparticles (Ansilin et al. 2016, Sundrarajan et al. 2015, Majumder 2012).

\section{MATERIALS AND METHODS}

\section{Chemicals}

$\mathrm{CuSO}_{4} 5 \mathrm{H}_{2} \mathrm{O}$ was procured from Hi-Media Laboratories, Mumbai, India. Copper oxide $(\mathrm{CuO})$ nanopowder $(<50 \mathrm{~nm})$ was procured from Sigma Aldrich Chemicals Pvt. Ltd., Bengaluru, India and distilled water from Millipore was used.

\section{Plant materials and preparation of the extract}

Leaves of Azadirachta indica, Pongamia pinnata, Lantana camara and orange peel (Citrus reticulata) were used for the synthesis of $\mathrm{CuO}$ nanoparticles. Leaves of these plants were collected from Nallal, Hoskote, Bangalore and orange peel was obtained from local market, Bangalore. Leaf extracts $20 \%$ by weight were prepared in d.w. filtered through Whatman filter paper No.1 and stored at $4^{\circ} \mathrm{C}$ for further use. Orange peels were dried under shade $\left(26 \pm 1^{\circ} \mathrm{C}\right)$ and powdered. $10 \%$ by weight of the orange peel extract was prepared by refluxing the dried powder in d.w. for $2 \mathrm{~h}$. It is then filtered through Whatmann No1 and kept at $4^{\circ} \mathrm{C}$.

\section{Synthesis of copper oxide nanoparticles}

Copper oxide nanoparticles were synthesized using leaf extracts of the selected plants and orange peel extract. The extracts and precursor solution of $\mathrm{CuSO}_{4} 5 \mathrm{H}_{2} \mathrm{O}(0,025 \mathrm{M})$ were preheated separately in a water bath at $60^{\circ} \mathrm{C}$ for 30 minutes and mixed at 1:4 proportions (Majumder 2012). The resultant solution was stirred at $1000 \mathrm{rpm}$ for 10 minutes and kept at room temperature for $3 \mathrm{~h}$. Presence of copper oxide nanoparticles was indicated by change in colour from bluish green to dark green. The solution thus obtained containing copper oxide nanoparticles was used for the experiment. 


\section{Characterization of biologically synthesized $\mathrm{CuO}$ nanoparticles}

The synthesized nanoparticles were characterized using Scanning electron microscopy (SEM) (Gemini Ultra 55 with ESB detector at 5,0kV) combined with Energy dispersive analysis X-ray (EDAX). A small quantity of nanoparticle formulation was dropped on to a small piece $(5 \mathrm{~mm} \times 5 \mathrm{~mm})$ of cleaned silicon wafer (drop casting). The wafer was dried thoroughly in air and was kept in a desiccator under vacuum for $48 \mathrm{~h}$. Specimens were coated with gold and SEM images were recorded.

\section{Fungus culture}

Actively growing fungal cultures of Trametes hirsuta (Wulfen: Fr.) Pilat (FRI No. 534) (white rot) and Oligoporus placenta (Fr.) Gilb. \& Ryvarden (FRI No. 180) (brown rot) were obtained from the National Type Culture Collection, Dehradun, India and maintained on malt $(2 \%)$ and agar $(1,3 \%)$ media, at Institute of Wood Science and Technology (IWST), Bengaluru.

\section{Agar mixed with test substances (Poisoned food method)}

The growth test on agar with the added test substance was performed to assess the antifungal activity of biologically synthesized $\mathrm{CuO}$ nanoparticles against wood decay fungi as per standard procedures (Nene and Thapilyal 2000, Das et al. 2010). Malt agar media was prepared with different concentrations of the extract containing the synthesized copper oxide nanoparticles ranging from 0,$25 ; 0,5 ; 1 ; 5 ; 7$ and $10 \%$. Commercially available copper oxide nanoparticles were also tested for comparing the efficacy of the synthesized copper oxide nanoparticle solution. Three replicates were prepared for each concentration and for each fungus. A mycelial disc of $6 \mathrm{~mm}$ diameter, cut out from the periphery of a 7 days old culture, was aseptically inoculated onto the centre of agar plates containing the test substances. Malt agar plates with $1 \mathrm{~mL}$ of distilled water were used as positive control. Malt agar plates with extracts alone and precursor solution of $\mathrm{CuSO}_{4} 5 \mathrm{H}_{2} \mathrm{O}$ served as negative controls. The inoculated plates were incubated at $25^{\circ} \mathrm{C}$ and the colony diameter was measured daily till the control plates reached the petri dish border. The percentage mycelia inhibition was calculated according to the following Equation 1.

$$
I=\frac{C-T}{C} x 100
$$

Where $\mathrm{I}$ is the inhibition, as percentage; $\mathrm{C}$ is the colony diameter of mycelia from control petri dishes, in millimeters; and $\mathrm{T}$ is the colony diameter (in $\mathrm{mm}$ ) of mycelia from the petri dishes containing the sample. If the inhibitory ratio was greater than $20 \%$, the test fungus would be considered inhibited and the minimal inhibitory concentration (MIC) for that fungus was then determined.

\section{Assessment of antitermite activity}

Graveyard test (accelerated) as per the Methods for field testing of preservatives in wood (IS 4833, 1993) was done for assessing the antitermite activity of the $\mathrm{CuO}$ nanoparticle formulation. The experiment was done at the Institute of Wood Science and Technology, Bangalore and field evaluation was done at the termite test yard of IWST at Nallal, Karnataka. The termite fauna identified in this test yard were Odontotermes horni (Wasmann), Odontotermes obesus (Rambur), Odontotermes redemanni (Wasmann) and Microtermes obesi (Holmgren) (Sundararaj et al. 2003). Rubber wood stakes (Hevea brasiliensis) of $153 \times 38$ x 6,25 mm with long axis parallel to the grain of the wood, free from insect or fungal attack and from knots were air seasoned to constant weight. The rubber wood stakes were treated with the formulation by pressure impregnation method (30 min of vacuum followed by 60 min of 50 pounds). 


\section{RESULTS AND DISCUSSION}

The synthesized $\mathrm{CuO}$ nanoparticles $(\mathrm{CuO}$ nps) using plant leaf extracts were characterized by SEM coupled with EDAX. SEM image confirmed the presence of $\mathrm{CuO}$ nanoparticles that are spherical in nature. The particles were well separated without agglomeration and the particle size remained within a range of $136 \mathrm{~nm}$ to $380 \mathrm{~nm}$ in the case of $\mathrm{CuO} \mathrm{nps}$ synthesized using $A$. indica leaf extract. In the case of $\mathrm{CuO} \mathrm{nps}$ synthesized using $P$. pinnata leaf extract and $C$. reticulata peel extracts the particle sizes were in the range of $466 \mathrm{~nm}$ to $2 \mu \mathrm{m}$ and $259 \mathrm{~nm}$ to $519 \mathrm{~nm}$ respectively. The particle size of $\mathrm{CuO} \mathrm{nps}$ synthesized using L. camara leaf extract was in the range of $33 \mathrm{~nm}$ to $46 \mathrm{~nm}$. EDAX profile also confirmed the presence of copper and oxygen in major fraction (Figure 1).

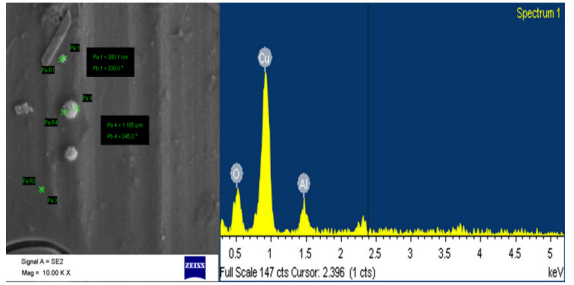

a)

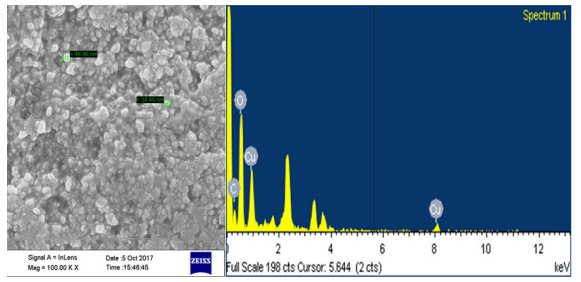

c)

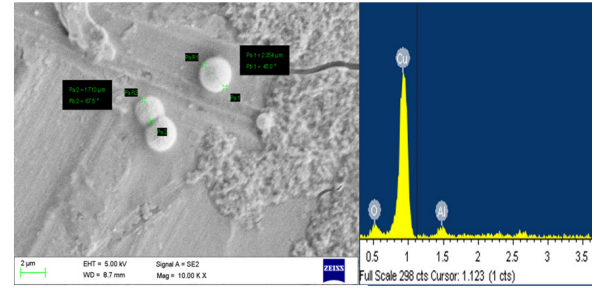

b)

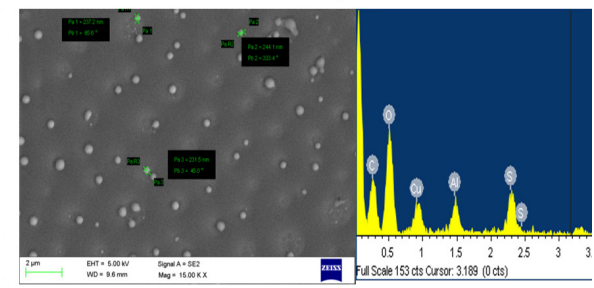

d)

Figure 1: Biologically synthesized $\mathrm{CuO}$ nanoparticles using plant extracts were characterized by SEM coupled with ED. a) Particle size of the synthesized copper oxide nanoparticles using Azadirachta indica leaf extract was between $136 \mathrm{~mm}$ and $380 \mathrm{~nm}$. b) Particle size of the synthesized copper oxide nanoparticles using Pongamia pinnata leaf extract was between $466 \mathrm{~mm}$ and $2 u m$. c) Particle size of the synthesized copper oxide nanoparticles using Lantana camara leaf extract was between $33 \mathrm{~nm}$ and $46 \mathrm{~nm}$. d) Particle size of the synthesized copper oxide nanoparticles using Citrus reticulata leaf extract was between $259 \mathrm{~nm}$ and $519 \mathrm{~nm}$.

Initiation of growth in control plates inoculated with Trametes hirsuta (white rot) and Oligoporus placenta (brown rot) was observed on $4^{\text {th }}$ day of the experiment. On the $9^{\text {th }}$ day the experiment was terminated as the control plates showed complete growth (Figure 2). The percentage of inhibition for T. hirsuta and O. placenta were calculated for all the plates (Table 1).

\begin{tabular}{|c|c|c|c|c|c|}
\hline $\begin{array}{l}\text { Sample } \rightarrow \\
\text { Fungil }\end{array}$ & $\begin{array}{l}\text { Con } \\
\text { trol }\end{array}$ & $\begin{array}{c}\text { CnO nanoparticle Std } \\
\text { nanopowder ( }<50 \mathrm{~nm}) \\
0,1 ; 0,25 ; 0,5 ; 1 ; 2 ; 5 \%\end{array}$ & $\begin{array}{c}\mathrm{CnSO}_{4} 5 \mathrm{HO} \\
5,7,10 \%\end{array}$ & $\begin{array}{c}\text { L.comora } \\
\text { leaf } \\
\text { extract } \\
5,7,10 \%\end{array}$ & 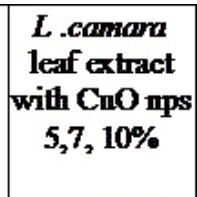 \\
\hline $\begin{array}{l}\text { Trametes hüsuta (White } \\
\text { rot) }\end{array}$ & & & & & \\
\hline $\begin{array}{l}\text { Oligoponss placenta } \\
\text { (brown rot) }\end{array}$ & & & & & \\
\hline
\end{tabular}

Figure 2: Plates showing inhibition of growth on Trametes hirsuta Wulf. ex Fr. and Oligoporus placenta

(Fr.) Gilb. \& Ryvarden at the end of the experiment ( $9^{\text {th }}$ day) by CuO-L. camara np formulation. 
There was no inhibition of fungal growth at concentrations 0,$25 ; 0,5 ; 1 ; 5 ; 7$ and $10 \%$ in all the plates till the end of the experiment in the case of plates having A. indica, P. pinnata, and orange peel (C. reticulata) extracts. Plates with $\mathrm{CuO}$ nanoparticles synthesized using $A$. indica, $P$. pinnata and orange peel (C. reticulata) extracts also showed no inhibition at concentrations ranging from 0,$25 ; 0,5 ; 1 ; 5 ; 7$ and $10 \%$. Plates containing precursor solution of $\mathrm{CuSO}_{4} 5 \mathrm{H}_{2} \mathrm{O}$ showed inhibition of up to $17 \%$ at a concentration of $10 \%$ which is not significant. L. camara leaf extract exhibited an inhibition of $9,66 \%$ at a concentration of $10 \%$ against the white rot fungus T. hirsuta.

Table 1: Effect of biologically synthesized $\mathrm{CuO}$ nanoparticle against the wood decay fungi Trametes hirsuta) and Oligoporus placenta*.

\begin{tabular}{|c|c|c|c|}
\hline \multirow[b]{2}{*}{ Sample } & \multirow[b]{2}{*}{$\begin{array}{c}\text { Concentration } \\
(\%)\end{array}$} & \multicolumn{2}{|c|}{$\begin{array}{c}\text { Percentage of inhibition } \\
\text { Ninth day }\end{array}$} \\
\hline & & $\begin{array}{c}\text { T. hirsuta } \\
\text { (White rot) }\end{array}$ & $\begin{array}{r}\text { O. placenta } \\
\text { (brown rot) }\end{array}$ \\
\hline Control & NIL & 0,00 & 0,00 \\
\hline \multirow[t]{3}{*}{ Copper sulphate precursor } & 5 & 3,00 & 2,30 \\
\hline & 7 & 5,00 & 3,30 \\
\hline & 10 & 17,00 & 17,30 \\
\hline \multirow{6}{*}{$\begin{array}{l}\mathrm{CuO} \text { nanoparticle } \mathrm{Std} \\
\text { nanopowder }(<50 \mathrm{~nm})\end{array}$} & 0,1 & 16,46 & 0,00 \\
\hline & 0,25 & 46,80 & 0,00 \\
\hline & 0,5 & 60,86 & 4,60 \\
\hline & 1 & 58,83 & 4,03 \\
\hline & 2 & 67,70 & 12,30 \\
\hline & 5 & 71,60 & 51,60 \\
\hline A. indica leaf extract & 0,$25 ; 0,5 ; 1 ; 5 ; 7 ; 10$ & 0,00 & 0,00 \\
\hline A. indica leaf extract with $\mathrm{CuO} \mathrm{nps}$ & 0,$25 ; 0,5 ; 1 ; 5 ; 7 ; 10$ & 0,00 & 0,00 \\
\hline P. pinnata leaf extract & 0,$25 ; 0,5 ; 1 ; 5 ; 7 ; 10$ & 0,00 & 0,00 \\
\hline P. pinnata leaf extract with $\mathrm{CuO} \mathrm{nps}$ & 0,$25 ; 0,5 ; 1 ; 5 ; 7 ; 10$ & 0,00 & 0,00 \\
\hline Orange peel (C. reticulata) extract & 0,$25 ; 0,5 ; 1 ; 5 ; 7 ; 10$ & 0,00 & 0,00 \\
\hline $\begin{array}{l}\text { Orange peel (C. reticulata) extract with } \\
\mathrm{CuO} \text { nps }\end{array}$ & 0,$25 ; 0,5 ; 1 ; 5 ; 7 ; 10$ & 0,00 & 0,00 \\
\hline \multirow[t]{6}{*}{ L. camara leaf extract } & 0,25 & 0,00 & 0,00 \\
\hline & 0,5 & 0,00 & 0,00 \\
\hline & 1 & 0,00 & 0,00 \\
\hline & 5 & 1,30 & 0,00 \\
\hline & 7 & 2,00 & 0,00 \\
\hline & 10 & 9,66 & 0,00 \\
\hline \multirow[t]{6}{*}{ L. camara leaf extract with $\mathrm{CuO} \mathrm{nps}$} & 0,25 & 0,00 & 0,00 \\
\hline & 0,5 & 0,00 & 0,00 \\
\hline & 1 & 0,00 & 0,00 \\
\hline & 5 & 1,84 & 15,55 \\
\hline & 7 & 48,88 & 22,96 \\
\hline & 10 & 100,00 & 34,44 \\
\hline
\end{tabular}

*Mean of three replications.

In plates with $\mathrm{CuO}$ nanoparticles synthesized using L. camara leaf extract there was $48,88 \%$ inhibition on the growth of the white rot fungus T. hirsuta and 22,96\% inhibition on the growth of brown rot fungus $O$. placenta at the end of experiment at a concentration of $7 \%$. At $10 \%$ concentration there was complete inhibition of growth (100\%) against $T$. hirsuta and an inhibition of 34,44\% was observed against $O$. placenta. 
It revealed that even though $\mathrm{CuO}$ nanoparticle synthesized by $L$. camara leaf extract completely inhibited the growth of $T$. hirsuta, it is not capable of inhibiting the growth of $O$. placenta completely at a concentration of $10 \%$. For further studies $10 \%$ of the sample is taken as minimal inhibitory concentration (MIC).

Commercially available $\mathrm{CuO}$ nanoparticles were also tested against wood decay fungi for concentrations ranging from 0,1 to $5 \%$. An inhibition of $71,6 \%$ was observed against $T$. hirsuta and $51,6 \%$ against $O$. placenta at a concentration of $5 \%$ copper oxide nanopowder in distilled water. There was no complete inhibition on growth of both indicating the instability of the $\mathrm{CuO}$ nanoparticles in distilled water, as the particles that dispersed in distilled water without adding any stabilizer tend to aggregates and settle down. It corroborates the fact that the stability of the nanoparticles in the dispersing medium is one of the main factor that describes the properties of nanoparticles (Yu and Xie 2012, Nair et al. 2017, Nair et al. 2018).

Since there was no significant level of inhibition in the plates containing $L$. camara leaf extract and precursor solution of $\mathrm{CuSO}_{4} .5 \mathrm{H}_{2} \mathrm{O}(0,025 \mathrm{M})$ alone, it can be concluded that the complete inhibition on growth of T. hirsuta observed in plates containing $\mathrm{CuO}$ nps synthesized by L. camara leaf extract is due to the presence of $\mathrm{CuO}$ nanoparticles synthesized or due to the synergistic effect of the plant extract and the synthesized $\mathrm{CuO}$ nanoparticles. The smaller size of $\mathrm{CuO}$ nanoparticles synthesized by $L$. camara leaf extract when compared to the size of $\mathrm{CuO}$ nanoparticles synthesized by other plant extracts might have also contributed to the inhibition on the growth of the decay fungi. The copper oxide nanoparticles synthesized in plant extracts were found to be stabilized by the components of the plant extract maintaining the properties of nanoparticles. This is in accordance with earlier reports that $\mathrm{CuO}$ nanoparticles synthesized with the help of plant extracts acts as both reducing and stabilizing agents (Lee et al. 2011, Khan et al. 2017). Many plant extracts have reported to have antifungal property and have wood preservative effects, also (Tascioglu et al. 2013). Gupta et al. (2017) reported that $L$. camara have wood protection properties as evidenced by its ability to improve the dimensional stability of wood. Since both $\mathrm{CuO}$ nanoparticles and $L$. camara extracts had wood preservative properties, the synergistic effect of both would be resulting in an effective ecofriendly, and less expensive wood preservative.

Table 2: Antitermite activity of biologically synthesized $\mathrm{CuO}$ nps plant extract formulation as per IS 4833 1993 (Graveyard test-accelerated).

\begin{tabular}{|l|c|c|c|c|c|c|}
\hline $\begin{array}{l}\text { No. of months after implantation } \rightarrow \\
\text { Samples } \downarrow\end{array}$ & $\mathbf{1}$ & $\mathbf{2}$ & $\mathbf{3}$ & $\mathbf{4}$ & $\mathbf{5}$ & $\mathbf{6}$ \\
\hline Control & 0,83 & 2,5 & 2,5 & 5,83 & 7,5 & 10,8 \\
\hline A.indica leaf extract & 0 & 0 & 0 & 0 & 2,5 & 5 \\
\hline A.indica leaf extract - CuO-nps & 0 & 0 & 0 & 0 & 0 & 0 \\
\hline P. pinnata leaf extract & 0 & 0 & 0 & 0 & 0 & 5 \\
\hline P. pinnata leaf extract - CuO-nps & 0 & 0 & 0 & 0 & 0 & 0 \\
\hline Orange peel (C. reticulata) extract & 0 & 0 & 0 & 0 & 0 & 2,5 \\
\hline Orange peel (C. reticulata) extract - CuO- nps & 0 & 0 & 0 & 0 & 0 & 0 \\
\hline L. camara leaf extract & 0 & 0 & 0,8 & 2,5 & 5 & 7,5 \\
\hline L. camara leaf extract - CuO- nps & 0 & 0 & 0 & 0 & 0 & 0 \\
\hline
\end{tabular}

Damage (\%) of rubber wood stakes. Mean of six replications.

There was no damage to the rubber wood samples treated with the formulation of copper nanoparticles 
synthesized using all the plant extract after an exposure period of six months in the field. (Table 2). Evaluation is progressing to get a better idea regarding the antitermite activity of the plant extract $\mathrm{CuO}$ nps formulation under field conditions.

\section{CONCLUSIONS}

Formulation of copper oxide nanoparticle and Lantana camara leaf extract was found to be effective as a wood protectant against two decay fungi as evidenced by growth test on agar with added test substances. This may be due to the smaller particle size of the $\mathrm{CuO}$ nps synthesized using $L$. camara extract. All the plant extract $\mathrm{CuO} \mathrm{np}$ formulations are found to give protection against termites in the field for a period of six months and further evaluations are in progress for a better conclusion. Development of a sustainable plant extract based synthesis route for metal nanoparticles enables the possibility of combining the intrinsic property of plant extract and metal nanoparticles for potential application in wood protection. The resultant formulation may protect wood from biodeterioration in a more effective way without any harmful effects to the environment. However, decay tests with impregnated wood samples must follow to prove protecting activity also with wood. In view of a feasible use for wood protection it must be also investigated if the $\mathrm{CuO}$ nps fix to the woody cell wall because otherwise only an indoor use will be possible.

Furthermore, more fungi than only each one white rot and one brown rot species should be investigated because there are hundreds of different species involved in wood decay. In view of practice it is also remarkable that the $\mathrm{CuO}$ nps were more effective against a white-rot fungus because in many regions (e,g. Europe) softwoods are the main construction woods and these are mostly attacked by brown-rot fungi. Last, the costs of such wood treatment compared to other wood protection measures must be considered.

\section{ACKNOWLEDGEMENTS}

The authors are thankful to University Grants Commission, India for the financial assistance provided in the form of Post Doctoral Fellowship No.F./PDFSS-2015-17-KAR-11613 and Director, Institute of Wood Science and Technology (IWST) for providing the necessary infrastructure. The assistance of CeNSE, IISc, Bangalore, India for the SEM-EDAX analysis is gratefully acknowledged.

\section{REFERENCES}

Akhtari, M.; Arefkhani, M. 2010. Application of Nanotechnology in Wood. In Proceedings IRG Annual Meeting, IRG/WP 10-30542. The International Research Group on Wood Protection: Biarritz, France.

Ansilin, S.; Kavya Nair, J.; Aswathy, C.; Rama, V.; Peter, J.; Jeyachynthaya Persis, J. 2016. Green synthesis and characterisation of copper oxide nanoparticles using Azadirachta indica (Neem) leaf aqueous extract. J Nanosci Tech 2(5): 221-223.

Cai, W.; Gao, T.; Hong, H.; Sun, J. 2008. Applications of gold nanoparticles in cancer nanotechnology. Nanotechnol Sci Appl 1:17-32.

Cao, G. 2004. Nanostructures and Nanomaterials: Synthesis, Properties and Applications. Imperial College Press, London.

Chan, W.C.W.; Nie, S. 1998. Quantum Dot Bioconjugates for Ultrasensitive nonisotopic detection. Science 281: 2016-2018. 
Clausen, C.A. 2007. Nanotechnology: Implications for the wood preservation Industry. In Proceedings 38th Annual Meeting of IRG/WP 07-30415, The International Research Group on Wood Protection: Jackson Hole, WY.

Clausen, C.A.; Green, F.; Kartal, S.N. 2010. Weatherability and leach resistance of wood impregnated with nano-zinc oxide. Nanoscale Res Lett 5:1464-1467.

Colvin, V.L.; Schlamp, M.C.; Alivisatos, A. 1994. Light-emitting diodes made from cadmium selenide nanocrystals and a semiconducting polymer. Nature 370: 354-357.

Das, K.; Tiwari, R.K.S.; Shrivastava, D.K. 2010. Techniques for evaluation of medicinal plant products as antimicrobial agent: current methods and future trends: a review. J Med Plants Res 4: 104-111.

Dhillon, G.S.; Brar, S.K. Kaur, S.; Verma, M. 2012. Green approach for nanoparticle biosynthesis by fungi: current trends and applications. Crit Rev Biotechnol 32: 49-73.

Dujardin, E.; Peet, C.; Stubbs, G.; Culver, J.N.; Mann, S. 2003. Organization of metallic nanoparticles using tobacco mosaic virus templates. Nano Lett 3: 413-417.

Goodsell, D. 2004. Bionanotechnology: Lessons from Nature. Willey-Less, New Jersey, USA. 1-8.

Gupta, H.; Sharma, K.R.; Sharma, J.N. 2017. Fungal Inhibition in Wood Treated with Lantana camara L. Extract. In: Pandey K, Ramakantha V, Chauhan S, Arun Kumar A (eds) Wood is Good. Springer. Singapore. 269-276.

Hulkoti, N.I.; Taranathm, T.C. 2014. Biosynthesis of nanoparticles using microbes-a review. Coll Surf B: Biointerf 121: 474-483.

Iravani, S. 2011. Green synthesis of metal nanoparticles using plants. Green Chem 13:2638-2650.

Indian standard. IS. 1993. Methods for field testing of preservatives in wood. IS 4833.1993. (First revision) Reaffirmed in 2008. India.

Kartal, S.N.; Green, F.; Clausen, C.A. 2009. Do the unique properties of nanometals affect leachability or efficacy against fungi and termites. International Biodeterioration \& Biodegradation 63: 490-495.

Khan, S.A.; Shahid, S.; Sajid, M.R.; Noreen, F.; Kanwal, S. 2017. Biogenic Synthesis of CuO Nanoparticles and their Biomedical Applications: A Current Review. Int J Adv Res 5(6): 925-946.

Klefenz, H. 2004. Nanobiotechnology: From Molecules to Systems. Eng Life Sci 4(3):211-218.

Lee, H.J.; Lee, G.; Jang, N.R.; Yun, J.H.; Song. J.Y.; Kim, B.S. 2011. Biological synthesis of copper nanoparticles using plant extract. Nanotechnology 1(1):371-374.

Lee, H.Y.; Li. Z.; Chen, K.; Hsu, A.R.; Xu, C.; Xie, J.; Sun, S.; Chen, X. 2008. PET/MRI dualmodality tumor imaging using arginine-glycine-aspartic (RGD) conjugated radio labeled iron oxide nanoparticles. J Nucl Med 49(8): 1371-1379.

Machado, G.O.; Cookson, L.J.; Christoforo, A.L.; Polito, W.L.; Silva, M.R; Calil, C.; Lahr, F.A.R. 2013. Wood preservation based on Neem oil: Evaluation of fungicidal and termiticidal Effectiveness. Forest Prod J 63: 202-206.

Macias, F.A.; Torres, A.; Maya, C.C.; Fernandez, B. 2005. Natural biocides from citrus waste as new wood preservatives. Fourth World Congress on Allelopathy, Charles Sturt University, Wagga, NSW, Australia.

Majumder, D.R. 2012. Bioremediation:Copper Nanoparticles from Electronic-waste. International Journal of Engineering Science and Technology 4(10):4388-4389.

Mishra, P.K.; Giagli, K.; Tsalagkas, D.; Mishra, H.; Talegaonkar, S.; Gry, V.; Wimmer, R. 2018. 
Changing Face of Wood Science in Modern Era: Contribution of Nanotechnology. Recent Patents on Nanotechnology 12:13-21.

Mittal, A.K.; Chisti, Y.; Banerjee, U.C. 2013. Synthesis of metallic nanoparticles using plant extracts. Biotechnol Adv 31: 346-356.

Moghaddam, A.B.; Namvar, F.; Moniri, M.; Tahir, S.; Azizi, P.M.; Mohamad, R. 2015. Nanoparticles biosynthesized by fungi and yeast: a review of their preparation, properties, and medical applications. Molecules 20:16540-16565.

Nair, S.; Giridhar, B.N.; Pandey, K.K. 2018. UV stabilization of wood by nano metal oxides dispersed in propylene glycol. Journal of Photochemistry \& Photobiology B: Biology 183:1-10.

Nair, S.; Pandey, K.K.; Giridhar, B.N.; Vijayalakshmi, G. 2017. Decay resistance of rubberwood (Hevea brasiliensis) impregnated with $\mathrm{ZnO}$ and $\mathrm{CuO}$ nanoparticles dispersed in propylene glycol. International Biodeterioration \& Biodegradation 122: 100-106.

Nene, Y.; Thapilyal, L. 2000. Poisoned food technique of fungicides in plant disease control ( $3^{\text {rd }}$ eds). New Delhi: Oxford and IBH Publishing Company.

Pissuwan, D.; Valenzuela, S.M.; Cortie, M.B. 2006. Therapeutic possibilities of plasmonically heated gold nanoparticles. Trends Biotechnol 24: 62-67.

Schrofel, A.; Kratosova, G.; Krautova, M.; Dobrocka, E.; Vavra, I. 2011. Biosynthesis of gold nanoparticles using diatoms-silica-gold and EPS-gold bionanocomposite formation. $J$ Nanoparticle Res 13: 3207-3216.

Singaravelu, G.; Arockiamary, J.S.; Ganesh Kumar, V.; Govindaraju, K. 2007. A novel extracellular synthesis of monodisperse gold nanoparticles using marine alga. Sargassum wightii Greville. Coll Surf B: Biointerf 57: 97-101.

Sotannde, O.A.; Yager, G.O.; Zira, B.D.; Usman, A. 2011. Termiticidal Effect of Neem Extracts on the Wood of Khaya senegalensis. Research Journal of Forestry 5: 128-138.

Sundararaj, R.; Remadevi, O.K.; Muthukrishnan, R. 2003. Comparatice efficacy of some insecticides in ground contact against subterranean termites. Pestology17(2):16-18.

Sundrarajan, M.; Ambika, S.; Bharathi, K. 2015. Plant-extract mediated synthesis of ZnO nanoparticles using Pongamia pinnata and their activity against pathogenic bacteria. Advanced Powder Technology 26:1294-1299.

Tan, M.; Wang, G.; Ye, Z.; Yuan, J. 2006. Synthesis and characterization of titania-based monodisperse fluorescent europium nanoparticles for biolabeling. Journal of Luminescence 117:1:20-28.

Tascioglu, C.; Mesut, Y.; Selim, S.; Caglar, A. 2013. Antifungal properties of some plant extracts used as wood preservatives. Int Biodeterior Biodegradation 85(1):23-28.

Terzi, E.; Kartal, S.N.; Yılgör, N.; Rautkari, L.; Yoshimura, T. 2016. Role of various nano-particles in prevention of fungal decay, mold growth and termite attack in wood, and their effect on weathering properties and water repellency. Int Biodeterior Biodegradation 107: 77-87.

Venmalar, D. 2017. Screening of Oils of Pongamia pinnata Linn, Jatropha curcas Linn and Simarouba glauca D.C. for developing Eco-Friendly Wood Preservatives. In: Wood is Good: Current Trends and Future Prospects in Wood Utilization. Pandey, K; Ramakantha, V; Chauhan, S; Kumar, A. (eds) Springer: Singapore. 261-268.

Vijayaraghavan, K.; Ashokkumar, T. 2017. Plant-mediated biosynthesis of metallic nanoparticles: A review of literature, factors affecting synthesis, characterization techniques and applications. Journal of Environmental Chemical Engineering 5:4866-4883. 
Yu, W.; Xie, H. 2012. A Review on Nanofluids: Preparation, Stability Mechanisms, and Applications. Journal of Nanomaterials 2012 (Article ID 435873). 